\title{
LUDICIDADE E MEDIAÇÕES TELEVISIVAS NO CONTEXTO ESCOLAR
}

Susana Angelin Furlan ${ }^{(1)}$, José Milton de Lima ${ }^{(2)}$, Márcia Regina Canhoto de Lima ${ }^{(3)}$,Carolline Rodrigues Guedes ${ }^{(4)}$.

Universidade Estadual Paulista, UNESP, ${ }^{(1)}$ Curso de Educação Física, ${ }^{(2)}$ Departamento de Educação, ${ }^{(3)}$ Departamento de Educação Física, ${ }^{(4)}$ Curso de Educação Física, Presidente Prudente - SP. E-mail: susana dp@hotmail.com. Conselho Nacional de Desenvolvimento Científico e Tecnológico - CNPq.

\section{RESUMO}

A presente investigação assumiu como objetivos compreender as manifestações televisivas nas culturas lúdicas das crianças dentro de uma instituição de Educação Infantil, no município de Álvares Machado, São Paulo. Concomitantemente apresentar a compreensão que os professores têm sobre as culturas lúdicas infantis e a estreita relação entre esta cultura, a prática educativa e a televisão, pretendendo contribuir para que o educador entenda a importância destes conteúdos e da ampliação do repertório das brincadeiras das crianças, a fim de auxiliar nas diversas áreas de seu desenvolvimento. Para alcançar tais objetivos a pesquisa teve como suporte teórico autores que se apoiam na Sociologia da Infância e na Comunicação Social. A metodologia utilizada foi de natureza qualitativa, caracterizando-se como Pesquisa do tipo Etnográfica. A investigação constatou que a mídia televisiva está presente no contexto escolar, porém não há uma mediação significativa com os conteúdos televisivos e as culturas lúdicas.

Palavras-chave: Criança, Televisão, Ludicidade, Professores, Mediação.

\section{PLAYFULNESS AND TELEVISION MEDIATIONS IN THE SCHOOL CONTEXT}

\begin{abstract}
This investigation took as objectives understand television demonstrations in playful cultures of children in a Kindergarten, in the municipality of Álvares Machado, São Paulo. At the same time introduce the understanding that teachers have about the playful children's cultures and the close relationship between this culture, educational practice and the television, intending to help the educator understands the importance of these contents and the expansion of the Repertoire of jokes of children, to assist in various areas of development. To achieve these goals the research had as theoretical support authors who rely on sociology of childhood and Social Communication. The methodology used was qualitative in nature, characterized as Ethnographic type lookup. The investigation found that the television media is present in the school context, but there's a significant mediation with television content and playful cultures.
\end{abstract}

Keywords: Child, Television, Playfulness, Teachers, Mediation. 


\section{INTRODUÇÃO}

O processo educacional não está presente unicamente dentro das instituições de ensino, visto que a família, os colegas, o contexto social e cultural em que os indivíduos estão inseridos são também responsáveis pela formação, educação e socialização. Neste ambiente de relações entre pessoas, objetos, costumes e hábitos que nos formamos como seres humanos construímos e identificamos nossas próprias vontades e gostos diante de toda a realidade apresentada.

As características, especificidades e particularidades de cada povo, de cada cultura encontram e relacionam-se nas instituições de ensino, assim identificada como o espaço de socialização secundária. Nesse ambiente, as crianças, que são o foco dessa pesquisa, convivem com a diversidade cultural em todos os aspectos: ético, racial, gênero, religioso, classe econômica, político, físico, psicológico, entre outros. Tais contatos possibilitam que o processo educacional esteja presente direta e indiretamente nesse contexto.

Desta forma a Educação Infantil, o primeiro ciclo escolar que a criança se insere, faz-se indiscutivelmente importante como elemento socializador, porque tudo o que for apreendido e vivido neste ambiente repercutirá em seu desenvolvimento.

A Educação Infantil, segundo as diretrizes curriculares nacionais, é a primeira etapa da Educação Básica e tem como finalidade o desenvolvimento integral da criança, em todos os seus aspectos.

Na Lei no 9.394/96 no artigo 22 a Educação Infantil é defendida como

[...] parte integrante da
Educação Básica, cujas
finalidades são desenvolver o
educando, assegurar-lhe a
formação comum
indispensável para o exercício
da cidadania e fornecer-lhe
meios para progredir no
trabalho e em estudos
posteriores. Essa dimensão de
instituição voltada à
introdução das crianças na
cultura e à apropriação por
elas de conhecimentos
básicos requer tanto seu
acolhimento quanto sua
adequada interpretação em
relação às crianças pequenas
(BRASIL, 2009, p. 03).

Importante também se faz destacar que a Educação Infantil é o lugar onde podemos encontrar as Culturas advindas da televisão, que hoje é a nova companhia da maioria das crianças, meio de comunicação, entretenimento, desenvolvimento de hábitos e fomentadora das culturas da infância.

Sendo assim, conhecendo a finalidade e função da Educação Infantil, buscamos nesse contexto, desenvolver a presente pesquisa que tem como objetivos: compreender como as professoras entendem e desenvolvem as brincadeiras em suas aulas e verificar a influência da televisão nas culturas lúdicas de crianças entre 3 a 5 anos de idade, visto que é inegável o contato delas com os meios de comunicação de massa, em 
especial a televisão. Para alcançar tais objetivos foi necessário conhecer e considerar a realidade em que as crianças estão inseridas, pois as culturas lúdicas estão diretamente ligadas às experiências e vivências, ou seja, são representações do meio social.

\section{METODOLOGIA}

Para se realizar uma pesquisa é preciso promover um confronto de dados, evidências, informações coletadas, e conhecimento teórico acumulado a respeito dele (LUDKE; ANDRÉ, 1986). Desta maneira, seguindo estes requisitos, pretendemos investigar os elementos culturais de uma instituição de Educação Infantil no município de Álvares Machado-SP, visando compreender e interpretar os fenômenos sociais com base nas perspectivas dos atores por intermédio do envolvimento e presença semanal da pesquisadora no ambiente escolar.

Para tanto, em busca de elucidar esses objetivos, utilizaremos da metodologia qualitativa, que não tem uma dimensão quantificável, mas sim interpretativa. Segundo Richardson (1989, p.6) uma metodologia qualitativa:

[...] pode descrever a
complexidader de
determinado problema,
analisar a interação de certas
variáveis, compreender e
classificar processos
dinâmicos vividos por grupos
sociais, contribuir no processo

de mudança de determinado grupo e possibilitar, em maior nível de profundidade, o entendimento das particularidades do comportamento dos indivíduos.

Utilizamos da pesquisa do tipo etnográfica, segundo Ludke e André (1986, p.14) "a etnografia é a descrição de um sistema de significados culturais de um determinado grupo".

A pesquisa se caracteriza como do tipo etnográfica, por que na área educacional, há alguns requisitos adaptáveis, ou seja, que não necessitam ser rigidamente seguidos, como, por exemplo, uma longa permanência do pesquisador no campo de pesquisa, o contato com outras culturas e o uso de muitas categorias sociais de análise, assim o que se faz é uma adaptação do estudo etnográfico (ANDRÉ, 2003).

É importante destacar que a pesquisa, pode ser assim nomeada - do tipo etnográfica - pois faz uso das principais técnicas tradicionalmente associadas à etnografia, ou seja, a observação participante, a entrevista intensiva e a análise de documentos.

Nesse estudo, a principal preocupação como destaca André (2003) é com o significado que têm as ações e os eventos para as pessoas, alguns são expressos diretamente pela linguagem, outros são transmitidos por meio de ações. Desta forma, a observação e os registros se 
fazem muito importantes para que se consiga atingir os objetivos da pesquisa, visando a descoberta de novos conceitos, novas relações, novas formas de entendimento da realidade.

Visto que esta pesquisa é feita com crianças, necessário se faz citar o número do comitê de ética: 13424213800005402 .

\section{RESULTADOS}

Respeitando a metodologia proposta, a etnográfica, que não visa a uma mudança da realidade, mas o entendimento através de minuciosas observações, essa pesquisa vem por compromisso social, propor a valorização da infância através de mudanças de concepções sobre o lúdico e da importância de mediar os conteúdos culturais advindos da televisão.

Concretizou-se através das conversas com as professoras e com os alunos, na escuta atenta e exposição do andamento da teoria e, ainda, na observação dos momentos lúdicos das crianças com as educadoras.

Destacamos a análise da entrevista através de desenhos feitos pelas crianças. Perguntamos o que mais gostavam de brincar, assim deveriam desenhar as preferências e ao lado delas escrevíamos o que era o desenho, não tendo a intenção de interpretar as ilustrações, mas apenas descrevê-las através das falas das próprias autoras, fomos escrevendo, conforme elas desenhavam.
Para melhor ilustrar os resultados segue algum das brincadeiras mais comentadas pelas crianças, ditas tradicionais.

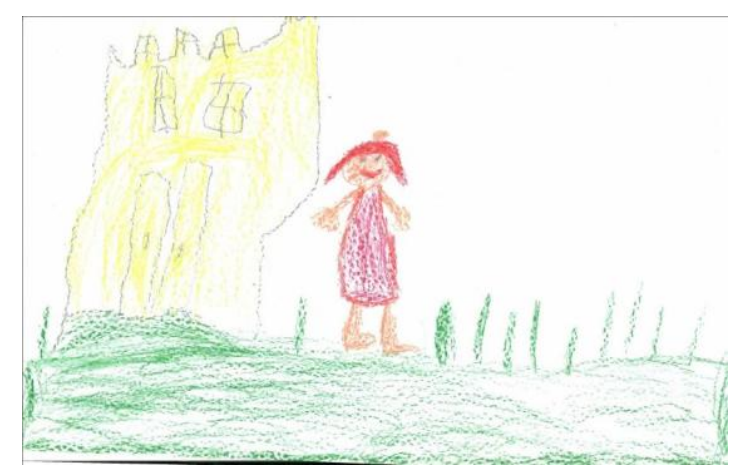

Figura 1. Desenho "Boneca"

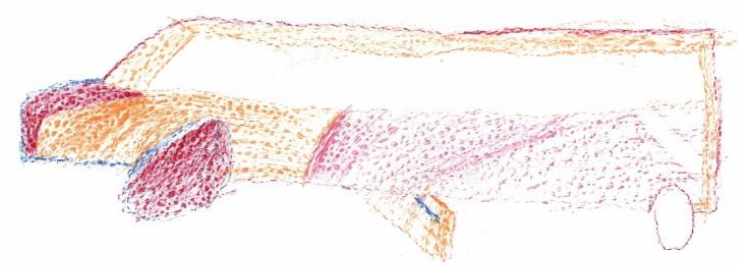

Figura 2. Desenho "Carrinho"

Apareceram $55 \%$ das respostas, referentes a brincadeiras como "boneca" e "carrinho", brincadeiras consideradas tradicionais. As crianças expuseram não só nomes genéricos como boneca, mas também o nome da marca "Barbie", "Monster High", "Elsa" (personagem do filme Frozen), entre outras. Assim como os meninos que diziam carrinho, simplesmente, ou nomes como "Mcqueen" (Nome do carro protagonista do filme Super Carros), Hot Wheels, entre outros.

Apesar das brincadeiras "comuns", ainda tiveram muitas brincadeiras que nos chamaram a atenção porque claramente 
provinham da Cultura televisiva, logo abaixo destacamos alguns desenhos que expressam a televisão dentro da ludicidade infantil.

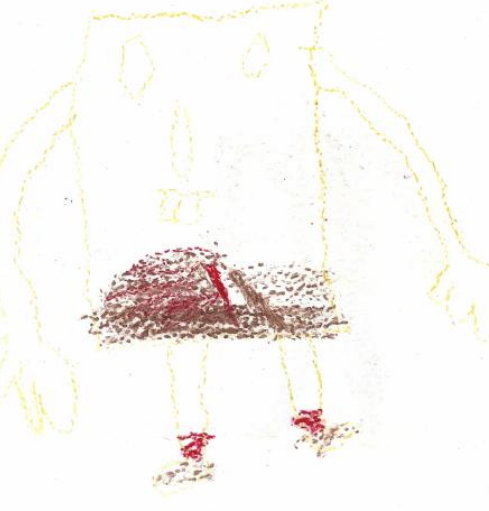

Figura 3. Desenho "Bob Esponja"

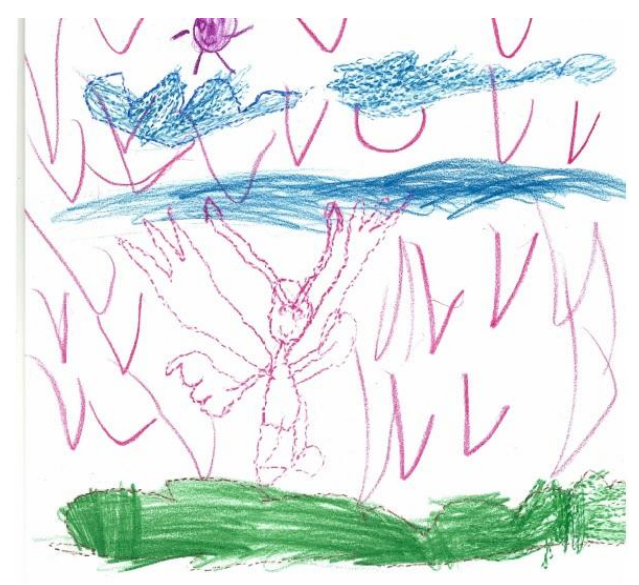

Figura 4. Desenho "Malévola"

Houve mais alguns desenhos relacionados com personagens da televisão (20\%) como Buzz Lightyear (Da animação Toy Story, Pixar), Bob esponja e Malévola. "Malévola" é um filme da Disney que mostra a outra versão da história da Bela adormecida, que apresenta a bruxa da história conhecida, como na verdade uma heroína. Quando questionamos as crianças, como elas brincavam com este enredo, elas nos disseram que era "voando e derrotando o príncipe mau".
Percebemos desta forma a incorporação dos conteúdos televisivos como enredo das brincadeiras, permitindo as crianças aumentarem seu arcabouço teórico, assim como enriquecer a imaginação, concordando com Girardello (2005)

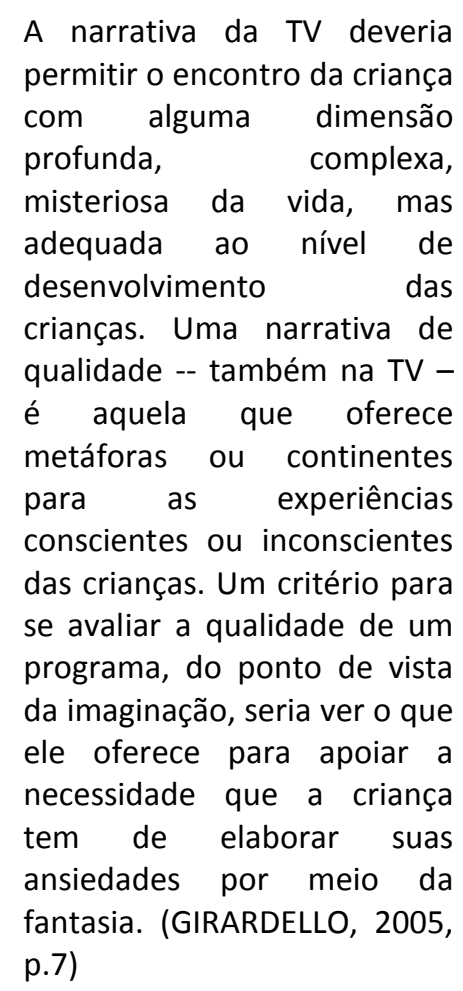

Além do consumismo percebido através de artefatos culturais, roupas e acessórios, percebemos a cultura televisiva nas falas sobre as restrições ou punição dos pais sobre o uso da TV pelas crianças. Gabriel ${ }^{1}$, do Infantil II quando questionado por um colega sobre o filme da "sessão da tarde" do dia anterior ele disse: "Não pude assistir, estava de castigo, mas eu já assisti a esse filme".

Em outro momento, conforme o Diário de Campo, Miguel$^{2}$ também do Infantil II disse a um colega que não pôde assistir à

\footnotetext{
${ }^{1}$ Todos os nomes aqui expressos são fictícios
} 
novela "Carrossel", porque era muito tarde e sua mãe achou que ele ficou muito tempo em frente à televisão.

Através de entrevistas com as crianças, elas nos relataram com quem assistiam televisão. O resultado pode ser visto no gráfico abaixo:

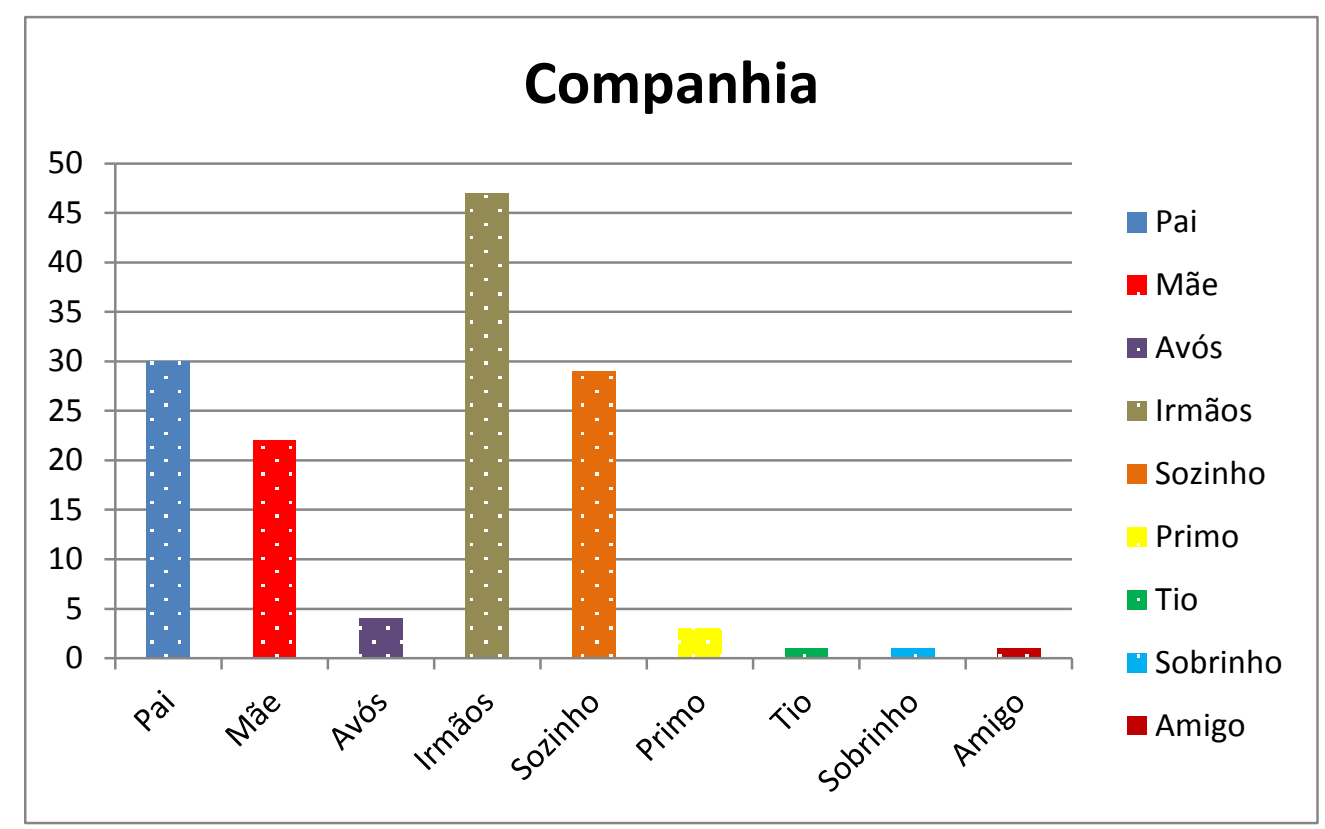

Figura 5. Gráfico sobre companhia ao assistir TV.

Através do gráfico percebemos que as crianças dizem assistir televisão com os irmãos, os pais e sozinhos, respectivamente. Porém, durante as entrevistas, a maioria das crianças que afirmavam assistir sozinhas, diziam que preferiam assistir com os pais, quando questionadas respondiam que sendo na companhia dos pais, poderia ser qualquer programa $(40 \%$ das crianças tiveram o mesmo tipo de fala).

Quando assistem sozinhas não há mediações realizadas no momento do televisionamento, assim só pode ocorrer algum juízo de valor depois, através de alguma fala ou pergunta isolada, o que dificulta a mediação pelos pais, e o acompanhamento dos conteúdos a que as crianças têm acesso, assim como a sua relação com a televisão.

As crianças por diversos momentos conclamam por mais tempo para a manifestação de sua cultura lúdica dentro da escola. Assim, a fim de viver esse aspecto de sua cultura, as crianças buscam a clandestinidade, a fuga da institucionalização.

Observamos isso em muitos momentos dentro da escola, quando os alunos eram repreendidos pelos adultos mesmo quando brincavam em situações 
propícias, como na hora do intervalo ou na chegada e na saída da instituição. Os inspetores e outros diziam que eles deveriam ficar quietos e só esperar, sem levar em conta que aquele era o único momento que eles estavam com seus pares e podiam brincar sem nenhuma restrição, mas Ihes era tirado o direito de correr ou de falar um pouco mais alto.

É preciso valorizar a escola como o encontro dos pares, como formas diferentes de viver essa cultura da brincadeira, para que, tendo espaço e tempo para isso, com o cuidado do fornecimento e provisão dos adultos eles possam aumentar seu arcabouço lúdico e experenciar diversos movimentos e deixar com que as suas faculdades como memória, imaginação, criatividade, entre outras, sejam utilizadas e aperfeiçoadas.

Estudando sobre a imaginação e jogos de faz de conta, percebemos que esses conteúdos estão intrinsecamente ligados às Culturas da Infância, desta forma, as crianças os manifestavam de maneira a se apresentar como concebe a Sociologia da Infância, um sujeito particular no mundo, com cultura e produtoras de cultura.

Reconhecendo a importância da imaginação faz-se necessário apresentar como as crianças manifestam essa faculdade mental durante as nossas observações, explicitaremos brevemente com uma situação ímpar:
Em um dia de observação, quando uma bolsista de um projeto de extensão, que ocorre concomitante a pesquisa na instituição, brincava com as crianças, ela disse que daria aos pequenos um pó mágico que os faria voar, logo dentro da brincadeira, todas se envolveram com a dinâmica. Uma semana depois ao adentrar a escola, uma das crianças nos surpreendeu chegando muito rápido ao nosso encontro e expressando: “Acredita que o pó que a professora deu não acabou ainda, eu não posso mais voar, mas estou correndo muito rápido".

Esta criança, como ocorreu com outras "mergulhou na brincadeira" e ressignificou o simples momento proposto pela bolsista e pode ser que tenha levado a brincadeira ou o "pó magico" para outras crianças e espaços, além do pátio da escola, incentivando e aumentando assim também seu repertório lúdico.

0 que percebemos também enriquecer a imaginação e o repertório lúdico dos pequenos são algumas aquisições de brinquedos e artefatos culturais que representam a televisão dentro do espaço escolar. Em uma situação percebemos as crianças brincando com uma bolsinha da "Tinker Bell"2. Ao adentrar a realidade, entendemos que a fantasia era algo explícito para as meninas, aquela bolsinha significava que elas eram as fadas e podiam transformar

\footnotetext{
${ }^{2}$ Personagem da Disney
} 
os objetos da escola. A brincadeira se desenvolvia enquanto as meninas encostavam nos objetos e trocavam a bolsa.

Em relação às professoras, elas relataram que trabalham com as brincadeiras e entendem a importância delas para o desenvolvimento integral das crianças, mas ao mesmo tempo dizem que realizam essa atividade no tempo que sobra entre um conteúdo da apostila e outro.

Em uma das conversas com a professora, questionávamos sobre a importância da brincadeira, ela disse que entendia, porém nos estendeu a apostila que o município usa para a Educação Infantil e nos disse: "eu queria dar mais momentos de brincadeiras, mas tenho que dar conta da apostila."

Entendemos a justificativa de que a burocracia e o sistema dificultam que a ludicidade seja trabalhada como deveria dentro da escola, mas não a impede. Percebemos que há uma crescente concepção de que o brincar irá colaborar com o desenvolvimento dos pequenos, mas a prática da maioria delas ainda é inconsciente e reduzida.

Algumas educadoras entendem que a televisão é prejudicial, por isso muitas vezes não utilizam de seus conteúdos para enriquecer a aula, ou para problematizar alguma fala, e assim ouvimos em entrevistas com as educadoras, que a televisão não está dentro da escola, não aparece. Porém, como relatado ao longo do artigo, as crianças nos mostraram que tem voz e que esta cultura televisiva se mostra dentro e fora da sala de aula, sendo que será ainda mais enriquecedora se a experiência com esta mídia for mediada.

A pesquisa etnográfica é uma metodologia enriquecedora, pois permite adentrar naquela cultura e assim pudemos entender que a falha na mediação televisiva assim como nas atividades lúdicas que não aparecem como poderiam, não é só uma questão de prioridade no tempo, mas uma lacuna dessas temáticas na formação inicial e continuada das professoras da instituição.

\section{DISCUSSÃO}

Em qualquer época da vida, seja criança, adolescente ou adulto, as brincadeiras sempre estão presentes. Brincar não é coisa apenas de crianças pequenas, erra a escola que subsidia sua ação dividindo o mundo em lados opostos: de um lado o jogo, a brincadeira, o sonho, e a fantasia e do outro: o mundo sério do trabalho e do estudo.

A importância do brincar reside no fato desta atividade ser uma das características das Culturas da Infância, visto que é o que elas fazem de mais sério na sua infância. Enquanto o trabalho é a principal atividade do homem, a brincadeira é a da criança (SARMENTO, 2003). 
A ludicidade - assumimos neste momento como sinônimo de brincar, apesar de suas diferenciações - é um dos eixos das Culturas da Infância, juntamente com a Reiteração, Interactividade e Fantasia do real, desta forma, faz parte da cultura ressignificada, reproduzida e produzida pelos pequenos.

Segundo Brougere (2006, p.257):

\begin{abstract}
A brincadeira é uma atividade que se distingue das outras, no sentido em que não deve ser considerada de modo literal. Nela se faz-de-conta, ou melhor, o que se faz só tem sentido e valor num espaço e em um tempo delimitado. Trata-se de uma atividade de segundo grau, que supõe uma distinção das formas comuns de atividade. Portanto, a brincadeira deve ser diferenciada das atividades comuns (de primeiro grau) e nisso ela se aproxima do teatro, ficção e do humor, de outras atividades de segundo grau que integram tudo o que não se deve levar ao pé da letra.
\end{abstract}

O "não levar ao pé da letra" significa que nós, adultos, não precisamos intervir na brincadeira da criança para dizer a ela que o que ela chama de trem - por exemplo: quando ela finge que as cadeiras da sala de jantar são vagões do trem - são, na verdade, cadeiras. A criança sabe que aquilo não é um trem, mas usa deste elemento da imaginação para brincar. Ela vai criando essa consciência intrínseca do que é real e o que faz parte de suas fantasias conforme tem as suas experiências.
Imperioso se faz destacar que não há a necessidade de brinquedo para a brincadeira se concretizar, o brinquedo pode ser produzido na dinâmica do jogo com os materiais e objetos disponíveis no momento. A necessidade do brinquedo se dá pelas condições de vida da criança e pela situação que se encontra, por exemplo, quando está sozinha ou sem companheiro da mesma idade. Porém, como destaca Brougere (2006), ele só pode ser objeto de brincadeira, pela decisão de brincar da criança.

Os brinquedos trazem elementos do cotidiano para que as crianças recodifiquem e reinterpretem. Quando são objetos já prontos pela indústria de consumo, eles dão suporte para ter acesso a elementos da cultura, como a televisão e o videogame.

Hoje as crianças dispõem de materiais e brinquedos que trazem uma contribuição no nível de ação, das imagens e da própria representação de quem brinca, como, por exemplo, bonecas que falam e carrinhos com comandos e caminhos ordenados que praticamente brincam sozinhos, mesmo assim a criança não perde a capacidade de ressignificá-los.

A brincadeira dentro da escola é de fundamental importância, segundo Loro (2010, p.77) é "um território de aprendizagem, que além de ser uma forma gostosa de aprender, proporciona algo fundamental ao ser humano: a construção de sua independência e liberdade". 
Se adotássemos o ensino numa perspectiva lúdica, como afirma Brancher (2011) romperíamos com o imaginário instituído em muitas escolas e em muitos professores, de que tudo tem que passar pelo seu crivo, já que quando as crianças brincam estão imaginariamente em outros papéis, em outros locais, o que é um estímulo à criatividade, à autonomia e a busca pelo novo de uma maneira diferente da tradicional mostrada pela escola.

Como destaca Morais (2007), em meio ao processo de construção do conhecimento, as crianças utilizam de diferentes linguagens e das interações que elas estabelecem com as outras pessoas e com o meio em que vivem. Sendo assim, o conhecimento não é fruto de cópia da realidade, mas um trabalho de criação, significação e ressignificação.

A importância da atividade lúdica como desenvolvimento e como aprendizado é ressaltada pelo mesmo autor:

Na atividade lúdica como na vida há um grande número de fins definidos e parciais, que são importantes e sérios, porque consegui-los é necessário ao sucesso e, conseqüentemente, essencial a satisfação que o ser humano procura, a satisfação oculta, neste caso seria 0 de aprender. (MORAIS, 2007, p.7)

Através desta pesquisa, percebemos que o paradigma da escola somente como saber didatizado - sem a ludicidade como diferente linguagem que contribui para a formação integral - é o mesmo que a perspectiva relatada por Wurning (2007, p.276):

O tempo da infância era vivido intensamente na rua. Era possível brincar o tempo todo na rua, palco de nossas brincadeiras e estripulias. (...) Fora da escola, vivenciei as maiores e melhores experiências lúdicas. Não me lembro de minhas professoras perguntarem sobre as coisas que fazíamos e nem brincar com as nossas brincadeiras. A escola era um espaço de seriedade e de aprender a ler e a escreve, não havia tempo para as brincadeiras, com exceção dos 15 minutos do recreio. [...] (2007, p.276 apud BRANCHER, 2011, p.5).

Quando as crianças brincam, principalmente no ambiente escolar, estão construindo um lócus de representações e símbolos, como destaca Brancher (2011, p.8) "um espaço onde os participantes exercem um momento de experimentação e de autoexperimentação do viver social".

Contudo, quando oportunizamos para as crianças um tempo da aula destinado aos brinquedos e as brincadeiras, estamos fazendo com que o ofício do aluno seja mais prazeroso e, por consequência, menos penoso. Mas esses momentos de sua cultura são, geralmente, inibidos e/ou desconsiderados, perdendo a chance de valorizar e aproveitar a fala e/ou brincadeira das crianças que podem auxiliar no processo de apropriação dos diversos tipos de 
conteúdos, servindo de suporte pedagógico.

Se a prática desconsiderar as Culturas Infantis ela estará dificultando o ofício do aluno para a criança, resultando no fracasso escolar.

Siqueira, Wiggers e Souza (2012) afirmam que nos momentos de ludicidade é promovida uma estrutura de interação entre as pessoas e assim uma maior possibilidade de expressividade corporal. Desta forma, a escola - por ser um ambiente propício à interação - devia garantir a existência dessa estruturação lúdica.

As Diretrizes Curriculares Nacionais para a Educação Infantil (2009) estabelecem que as instituições escolares devam garantir a sua função sociopolítica e pedagógica da qual fazem parte a construção da socialização e subjetividade comprometidas com a ludicidade, dentro de outros fatores, tendo assim o que discute o marco regulatório.

Sobre a fundamental participação dos professores nesse processo Carvalho (2005, p. 8), afirma que:

$\mathrm{Na}$ medida em que os professores compreenderem as reais possibilidades da participação da criança na escola, bem como as possibilidades oferecidas pela atividade lúdica no trabalho escolar, poderemos garantir melhores condições para que as crianças exerçam seu direito à imaginação [...]. Brincar não é para elas uma atividade secundária, mas fundamental e ocupa grande parte do seu desenvolvimento. Cabe à escola compreender isso e oferecer melhores condições para que o processo ocorra de fato.

Para muitos educadores, a brincadeira ainda ocupa um espaço marginal dentro das instituições, não sendo uma atividade legitimamente escolar. Há profissionais que afirmam contemplar a atividade em suas práticas pedagógicas, mas que a praticam em tempo restante, deixando como estratégia, caso sobre tempo. Sendo que, como afirma Fortuna (2003).

[...] a efetiva brincadeira está ausente na maior parte das classes de educação infantil. E o que é pior: à medida que as crianças crescem, menos brinquedos, espaço e horário para brincar existem. Quando aparece, é no pátio, no recreio, no dia do brinquedo, não sendo considerada uma atividade legitimamente escolar (FORTUNA, 2003, p.8).

Nessa mesma direção, Carvalho (2005, p.3) afirma que as crianças não brincam dentro da escola, pois não há estratégia para chegar ou sair mais cedo da aula, não há tempo suficiente no intervalo, pois têm de lanchar, ir ao banheiro, conversar com os colegas e só depois quando sobra tempo, brincar. Visto que a sala de aula não é lugar para brincar, como é uma crença internalizada pelas crianças, o brincar fica entendido como fracasso escolar, quando a criança brinca é um tempo perdido de aprendizagem. 
Desta forma, a maioria das crianças não consegue uma forma de se organizar para brincar e driblar esse sistema, nem dentro e nem fora da sala de aula. Esse processo de institucionalização da escola está muito intrínseco na maioria dos alunos.

Lima (2008) considera que os cursos de formação de professores não tem contemplado adequadamente a temática do jogo e da brincadeira, se comprometendo com essas atividades essenciais para 0 desenvolvimento integral do indivíduo. 0 professor exerce o papel de mediador entre a criança e sua cultura, inclusive a cultura lúdica, assim a sua intervenção é essencial para que os educandos ampliem e diversifiquem os seus conhecimentos sobre esses conteúdos. Segundo o autor referido, é fundamental que se ofereça condições materiais, espaciais e temporais apropriadas e desafiadoras, possibilitando aos educandos um grande repertório de brincadeiras e aprendizado com diferentes elementos.

Esta carência de conhecimentos sobre a brincadeira repercute em práticas equivocadas e distantes das crianças, como nos alerta Moreira (2014), tornando as instituições escolares espaços estranhos para as crianças e sem significado. Assim, lembra o autor que inicialmente a escola foi pensada para ser um espaço aberto, de liberdade e de divertimento.

Por tantas vezes as crianças podem estar denunciando a falta de sentido das práticas escolares, sendo enxergadas como indisciplinadas, desobedientes (MOREIRA, 2014). A alternativa que encontram, como observamos em nossa pesquisa é buscar a clandestinidade-momentos de fuga- da institucionalização anteriormente mencionada, a fim de viver esta cultura que Ihes é cerceada.

Por diversas vezes observamos as crianças correrem e brincarem na hora do intervalo e este momento ser repreendido pelos adultos, porém, em outros momentos, fugindo dos olhares atentos dos inspetores e professores, continuavam na brincadeira, ou mesmo a ressignificavam, tendo agora por objetivo, realmente fugir dos olhares dos mais velhos.

Siqueira, Wiggers e Souza (2012) afirmam que é incontestável a apropriação e relação de conteúdos expostos na mídia com as brincadeiras das crianças, posição esta sustentada também por Brougère (2000) que afirma que a televisão modifica e interfere significativamente na cultura lúdica da criança, considerando que os meios de comunicação fazem parte da cultura contemporânea.

Porém, essas representações nas brincadeiras das crianças não são apenas incorporações de simbolismos sem sentido, mas uma saída da criança da posição de observador da imagem na televisão para ator na atividade lúdica como o resultado de uma impregnação cultural (BROUGERE, 2000). 
Segundo o mesmo autor, um desenho animado ou um filme é o bastante para que as crianças ajustem o comportamento e entrem em uma brincadeira de forma igualitária com as outras crianças. O conteúdo se torna um instrumento de integração para iniciar uma conversa, uma brincadeira basta "se transformar", com o poder da imaginação.

Sobre esses conteúdos das brincadeiras das crianças na escola, afirma Bitencourt et al. (2005)

De acordo com Orozco (1996),
vê-se necessária uma
intervenção pedagógica da
própria escola sobre,
especificamente, os
conteúdos da televisão, pois é
nesse ambiente que há um
conflito entre o que é
ensinado e aprendido na
escola e na TV. Nesse caso, se
não ocorrer uma mediação
adequada, um possível
resultado para a instituição
seria uma "perda" de sua
responsabilidade educacional.
A escola precisa aceitar as
realidades de seu tempo e se
preparar para enfrentar as
dificuldades considerando
que "[...] é na escola que o
pensamento é fértil e
sobrevive." (BITENCOURT et
al., 2005, p. 726 apud
SIQUEIRA, WIGGERS; SOUZA,
2012, p.317)

Neste contexto, a brincadeira da criança encontra papel fundamental na educação infantil, pois as crianças desenvolvem e conhecem o mundo a partir das relações sociais que estabelecem com as histórias das brincadeiras, na interação com outras culturas dos seus colegas, pais e professores da instituição escolar.

Por meio do eixo ludicidade, a criança faz experiências do processo cultural, da interação simbólica em toda a sua complexidade, sendo a experiência lúdica um processo cultural suficientemente rico em si mesmo para merecer ser analisado mesmo que não tivesse influência sobre outros processos culturais mais amplos.

\section{CONCLUSÃO}

Com os resultados alcançados pelos estudos, foi possível identificar que as mídias estão sim presentes no cotidiano das crianças, seja dentro do contexto familiar ou no contexto escolar. Essa relação é observada na ludicidade e é defendida pelos autores pela sua visão crítica, que através da mediação que deveria ser feita pelos pais/responsáveis, professores e demais adultos, pode privilegiar a aprendizagem e valorizar os conhecimentos que os conteúdos midiáticos proporcionam para os interlocutores se forem ressignificados.

De tal modo, os resultados foram significativos e nos fazem acreditar que estamos no caminho certo e que a pesquisa segue rumos interessantes, mas se faz imperativo destacar que muitos saberes ainda precisam ser levantados para melhor entendermos a problemática na relação da mídia televisiva e os diversos aspectos 
culturais que as crianças apresentam no ambiente escolar.

Concluímos assim em consonância

com Munarim (2007) que na

contemporaneidade a infância é construída com a ajuda da mídia.

\section{REFERÊNCIAS}

ANDRÉ, M. E. D. Etnografia da prática

escolar. Campinas: Papirus, 2003.

BRANCHER, V. R. Cultura Infantil:

problematizando a Ludicidade e o ser criança hoje. UFSM, Santa Maria, p.1-12, ago. 2011.

BRASIL. Ministério da Educação. Conselho Nacional de Educação. Diretrizes Curriculares Nacionais para a Educação Infantil. Brasília, 2009.

BROUGERE, G. Brinquedos e Companhia. São Paulo: Cortez, 2006.

BROUGÈRE, G.. Brinquedo e cultura. 3. ed. São Paulo: Cortez, 2000.

CARVALHO, D. C. O direito à imaginação na escola. In: SEMINÁRIO EDUCAÇÃO, IMAGINAÇÃO E AS LINGUAGENS ARTÍSTICOCULTURAIS, 1., 2005. Santa Catarina. Anais... Santa Catarina, 2005. v. 1, p.1-9.

FORTUNA, T. R.. O Brincar na Educação Infantil. Pátio Educação Infantil, São Paulo,v.1, n.3, p. 6-9, dez. 2003/mar. 2004.

GIRARDELLO, G. Imaginação infantil e as histórias da TV. 2005. Disponível em: $<$ www.aurora.ufsc. br/artigos/artigos_imaginacao.htm>. Acesso em:10 jun. 2008.

LIMA, J. M. O jogo como recurso pedagógico no contexto educacional. São Paulo: Cultura Acadêmica, 2008.
LORO, A. P. Formação de professores e representações sobre o Brincar. São Paulo: Icone, 2010.

LUDKE, M.; ANDRÉ, M. E. D. A. Pesquisa em Educação: abordagens qualitativas. São Paulo: EPU, 1986.

MORAIS, R. L. de. A importância do lúdico na educação infantil. Dominium - Revista cientifica da faculdade de Natal - FAL, n. 2, p.1-18, maio/ago., 2007.

MOREIRA, T. A. Imaginação e protagonismo na Educação Infantil: estreitando os vínculos entre adultos e crianças. 2014. $212 \mathrm{f}$.

Dissertação (Mestrado) - Curso de Educação, Universidade Estadual Paulista, Presidente Prudente, SP.

MUNARIM, I. Brincando na escola: o imaginário midiático na cultura de movimento das crianças. 2007. 194f. Dissertação (Mestrado em Educação) Universidade Federal de Santa Catarina. Florianópolis, SC.

RICHARDSON, R. J. Pesquisa Social: métodos e técnicas. São Paulo: Atlas, 1989.

SARMENTO, M.J. As culturas da Infância nas encruzilhadas da 20 modernidade. 2003.

Disponível em

<http://cedic.iec.uminho.pt/cedic/Textos_de _Trabalho/textos/encruzilhadas.pdf $>$. Acesso em: 05 maio 2007.

SIQUEIRA, I. B.; WIGGERS, I. D.; SOUZA, V. P.. O brincar na escolar: a relação entre o lúdico e a mídia no universo infantil. Rev. Bras.

Ciênc. Esporte, Florianópolis, v. 34, n. 2, p.313-326, abr. 2012.

Recebido para publicação em 19/08/2015

Revisado em 26/08/2015

Aceito em 10/09/2015 